Дубровский А. И. Нейроэтика: некоторые актуальные философско-методологические вопросы // Философия. Журнал Высшей школы экономики. - 2020. - T. IV, № 1. C. $24-41$.

\title{
ААВИА АУвРОВСКИй*
}

\section{НЕЙРОЭТИКА: НЕКОТОРЫЕ АКТУАЛЬНЫЕ ФИЛОСОФСКО-МЕТОАОЛОГИЧЕСКИЕ ВОПРОСЫ}

Аннотация: В статье выделяются два основных аспекта нейроэтики: нейронаучные исследования этически значимых свойств сознания и задачи этической регуляции и этического контроля современных нейронаучных исследований сознания и мозга. Аалее рассматриваются три актуальных вопроса, касающиеся обозначенных аспектов нейроэтики: (1) Этические проблемы того направления нейронаучных исследований, которое именуется "Чтением мозга» (Brain-Reading). Оно занимается определением мозговых коррелятов психических явлений и расшифровкой их нейродинамических кодов. Здесь возникают острые этические и социальные вопросы о правомерности вторжения в субъективный мир личности, которые требуют основательного обсуждения. (2) Нейронаучные и генетические исследования феномена обмана как неустранимого фактора межличностных и социальных коммуникаций. Подчеркивается важность учета различных форм обмана и соответствующих им диспозициональных свойств сознания, отмечается опыт нейронаучного исследования этих свойств и тех диспозициональных свойств, которые определяют установку на правду и реализацию высоких нравственных свойств личности. Показана этическая правомерность разоблачения злонамеренного обмана с помощью нейронаучных методов, особенно в случаях криминальных действий. (3) Подвергаются критическому анализу попытки отрицания свободы воли путем ссылок на нейронаучные исследования. Вопрос о свободе воли является ключевым для этики. Показана несостоятельность ряда модных ныне концепций, которые отрицают свободу воли и тем самым содействуют распространению нравственного релятивизма.

Ключевые слова: нейроэтика, нейронаука, генетика, сознание, чтение мозга, нейронаучные исследования обмана, свобода воли и нейронаука, критика отрицания свободы воли.

DOI: $10.17323 / 2587-8719-2020-1-24-41$.

Нейроэтику можно рассматривать как раздел нейрофилософии, который ставит в центр внимания нейронаучные исследования сознания в его различных проявлениях. Нейроэтика как особое направление теоретических размышлений и исследований стала оформляться в общих чертах с начала нашего века; она охватывает весьма широкий круг вопросов (Levy, 2007). В ней можно выделить два основных аспекта:

* Дубровский Давид Израилевич, д. филос. н., профессор, главный научный сотрудник Института философии РАН, заместитель председателя НСМИИ РАН и председатель программного комитета секции «Нейрофилософия» НСМИИ РАН, ddi29@mail.ru.

** (C) Дубровский, Д. И. (C) Философия. Журнал Высшей школы экономики. 
(1) Нейронаучные исследования этически значимых свойств сознания и деятельности с помощью соответствующих методов, начиная с фМРТ и других способов визуализации нервных процессов в мозге, связанных с психическими явлениями. Вместе с этим используется широкий спектр методов и знаний из области психиатрии, нейрогенетики, нейрофармакологии, неврологии и других разделов нейронауки, многие из которых тесно связаны с информационными технологиями, развитием нерокомпьютерных интерфейсов, проблематикой искусственного интеллекта.

(2) Вопросы этической регуляции и этического контроля исследований психики методами нейронауки и смежных с ней разделов биологии и медицины, имея в виду прежде всего прогнозирование и оценку результатов этих исследований. Поскольку они связаны с вмешательством в головной мозг и нервную систему, на первом плане здесь стоит задача определения эффективных средств регуляции и контроля. В этой области ведется разработка соответствующей нормативной базы.

Надо сразу подчеркнуть, что нас интересует не просто знание человеком этических норм, а его реальные решения и действия в соответствии с этими нормами. Нейронаука изучает не сами по себе этические нормы, она стремится исследовать те мозговые нейродинамические структуры и системы, которые определяют значимые в моральном отношении субъективные переживания человека и связанные с ними его решения и действия. Здесь тоже возникает крайне сложный вопрос: как добиться их эффективной этической регуляции.

Множество конкретных вопросов, которые включает нейроэтика, пока еще слабо упорядочены. Их четкое описание и систематизация представляют важную теоретико-методологическую задачу. Я хочу кратко остановиться лишь на трех актуальных вопросах, которые касаются обоих обозначенных выше аспектов нейроэтики.

1. «ЧТЕНИЕ МОЗГА» («BRAIN READING») КАК НАПРАВЛЕНИЕ НЕЙРОНАУЧНЫХ ИССЛЕДОВАНИЙ И ЕГО ЭТИЧЕСКИЕ ПРОБЛЕМЫ

Это сравнительно новое направление занимается определением нейродинамических коррелятов психических явлений, формирует различные нейрокомпьютерные интерфейсы и достигло уже существенных результатов в расшифровке мозговых кодов ряда явлений субъективной реальности. Это направление требует разработки так называемой «Трудной проблемы сознания»: объяснения характера связи явлений 
субъективной реальности (которым нельзя приписывать физические свойства) с мозговыми процессами, способности явлений субъективной реальности служить причиной телесных изменений, решения ряда других актуальных вопросов (Dubrovsky, 2019а; Дубровский, 2015).

Наша психика устроена так, что в осознаваемых состояниях (скажем, в переживаемом мной сейчас зрительном образе дерева, которое я наблюдаю за окном) мне и любому дана информации как бы в «чистом» виде, - в том смысле, что ее мозговой носитель от нас целиком скрыт. Этот носитель представляет собой сложную нейродинамическую систему, кодовую структуру этого образа. Еще более 10 лет тому назад были расшифрованы мозговые коды сравнительно простых черно-белых образов. От головы испытуемого отводят сигналы на компьютер, и тот зрительный образ, который он сейчас переживает, изображается на экране компьютера (Miyawaki, Uchida \& Yamashita, 2008). Примерно через три года были расшифрованы цветные динамические образы (фрагменты кинофильма) (Nishimoto, Naselaris \& Benjamini, 2001). Taкое «чтение мозга» успешно развивается. С помощью новых методов уже расшифровывается ряд психических явлений, выражающих желания, оценки, мысли человека. Правда, пока еще это отдельные и сравнительно простые психические явления, до расшифровки мыслительной деятельности в ее целостном контексте внутреннего субъективного мира личности еще далеко. Но к этому быстро идет дело, и уже сейчас перед нами встают острые этические и социальные вопросы (Dubrovsky, 2018). В чьих руках окажутся технологии расшифровки мозговых кодов? Кто и зачем будет открывать наш внутренний мир? Ведь вся социальная самоорганизация основана на принципе относительной закрытости внутреннего мира личности, которая по своей воле избирательно открывает его разным людям. Нарушение этого принципа способно повлечь вопиющее неравенство, крах всей системы социальной самоорганизации.

Все это уже сейчас обязывает поставить нейронаучные исследования расшифровки мозговых кодов под эффективный этический и юридический контроль. Пожалуй, главная трудность связана с тем, что эти исследования играют важную роль в развитии медицины, искусственного интеллекта, ряда других практически важных научных дисциплин. Как разделить полезное и вредное, этически приемлемое и неприемлемое? Здесь перед нами чрезвычайно сложная междисциплинарная проблема стратегического масштаба. Она требует объединения усилий 
философов-методологов, специалистов в области этики и права, крупных представителей нейронауки. Необходима организация специальной группы исследователей для разработки и решения этой проблемы.

\section{2. ФЕНОМЕН ОБМАНА И НЕЙРОЭТИКА}

Обман, если говорить кратко, это дезинформация другого субъекта. Он включает разные формы и проявления, часть которых имеет четкий этически негативный характер (виды злонамеренного обмана и т. д.), другие могут рассматриваться как этически нейтральные (так называемые защитные виды обмана) или даже иметь положительное этическое значение (добродетельный обман, сокрытие от противника военной тайны, обман для спасения жизни человека от злоумышленника и т. п.) (Дубровский, 2010).

Надо признать, что обман - фундаментальный фактор межличностных и социальных коммуникаций. В этом легко убедиться с помощью простого мысленного эксперимента. Представим себе, что при нынешнем нравственном уровне человечества с завтрашнего дня никто никого ни в чем не обманывает. Люди говорят друг другу только правду; институциональные субъекты - государственные органы, политические партии, общественные организации, торговые и производственные фирмы - ни в чем никого не обманывают, говорят правду и только правду. Вдумайтесь, что произойдет в социуме? Очевидно, полный хаос.

Все это позволяет думать, что склонность к обману, потребность в нем как в факторе конкуренции, защиты интересов, компенсации человеческих слабостей, укоренена в природе человека, в его психической деятельности и, следовательно, представлена в его мозговой функциональной структуре и нейродинамической организации. Это, впрочем, относится и к врожденному характеру альтруистических свойств человека, его нравственным установкам, которые создают скрепы социальной жизни, хотя часто и не выдерживают конкуренции с инстинктами и сомнительными, а иногда и явно негативными в нравственном отношении интенциями.

Таким образом, здесь в интересующем нас нейроэтическом плане есть актуальные вопросы. Один из них - исследования средствами нейронауки обмана как намеренного действия (информационного и практического). Когда человек лжет, он знает правду. В его мозгу формируется двухуровневая нейродинамическая структура. На первом уровне находится содержание правды. Над ним надстраивается нейродинамическая структура содержания лжи, которая должна быть правдоподобной. 
Ведь надо обязательно уверить другого в своей правдивости, иначе ложь теряет свое предназначение. Некоторые люди, как мы знаем, прекрасно владеют искусством правдоподобного обмана. Но все это требует особой операции сокрытия лжи, что представляет собой формирование соответствующей нейродинамической структуры; затраты на ее создание требуют значительных усилий, дополнительной энергии.

В нейронауке давно уже сложились представления об этих процессах и получены соответствующие экспериментальные данные (например, paботы Н. П. Бехтеревой и ее сотрудников еще в 70-80-х годах прошлого века; многочисленные исследования в западной нейронауке последних десятилетий). Они свидетельствуют, что указанные усилия при производстве лжи вызывают определенные вегетативные и соматические изменения, проявляющиеся внешне в нюансах речевых интонаций, мимике, выражениях глаз, а главное - в объективных показателях (кожно-гальванические рефлексы и др.). На этом были основаны старые детекторы лжи. Современные нейротехнологии дают возможность более эффективного определения лжи на основе методов визуализации мозговых процессов (фМРТ и др.). Здесь, правда, также возникают этические вопросы о правомерности использования современнных детекторов лжи. Он решается в зависимости от конкретной ситуации и, безусловно, оправдан в случаях, когда правоохранительные органы имеют дело со злостным, опасным для общества преступником.

Нейроэтика тесно связана с генетикой, которая свидетельствует о том, что, всем людям присуща фундаменталъная установка на правду и истинность. Она остается в силе, несмотря на феномен самообмана, который тоже свойствен всем людям, служит фактором компенсации нашей ограниченности, слабости ума и воли. Эта установка присуща и отъявленным лгунам, хитроумным, бессовестным политиканам и прочим персонажам такого сорта, ибо все они тоже кровно заинтересованы в правде о намерениях и поведении других людей, об истинном положении дел.

Роль генетических факторов в формировании нравственных свойств личности не вызывает сомнения. На этот счет имеются обширные научные данные (Эфроимсон, 2004), об этом говорят и многочисленные исторические свидетельства. Примером может служить знаменитые «Двенадцать Цезарей» Светония, где автор всегда специально останавливается на тех свойствах правителя, которые он полагает врожденными, данными «от природы». Вот, что он пишет, например, о Нероне: «Наглость, похоть, распущенность, скупость, жестокость его поначалу 
проявлялись постепенно и незаметно, словно юношеские увлечения, но уже тогда всем было ясно, что пороки эти - от природы, а не от возраста» (Светоний, Гаспаров, 1966: 158). Интересные размышления о природе человека мы встречаем у Макиавелли, особенно в его замечательном труде «История Флоренции», в котором изложение событий органически связано с личностными описаниями их участников, даны проницательные психологические портреты деятелей тех времен. К этому надо добавить гениальные прозрения художественной литературы (Пушкин, Толстой, Чехов и др.).

Важно, на мой взгляд, осмысливать также и свой жизненный опыт. Я встречал не только множество хороших, порядочных людей, но встречал, правда, не столь часто, и людей исключительной, удивительной доброты, безукоризненного благородства, сохранявших всегда, несмотря ни на какие внешние обстоятельства и плохое к ним отношение, эти замечательные качества. И у меня сложилось убеждение, что они во многом тоже от природы. Подобно тому, как есть поэтические или математические гении, есть, наверное, и гении доброты.

Если обратиться к историческим источникам, то это особенно ясно выражено у личностей, имевших такие качества, но которые, обладая неограниченной властью, могли отбросить фиговый листок морали, позволить себе делать все, что угодно. Среди Римских цезарей выделяются два таких человека Антонин Пий и Марк Аврелий. Исключительные качества доброты, скромности, благородства, милосердия этих личностей ярко отображены в исторической литературе. Большой знаток того времени Эрнест Ренан, подробно описавший жизнь Марка Аврелия и стремившийся осмыслить удивительные для всевластного цезаря свойства его личности, считал, что они не могут быть объяснены воспитанием, религией, изучением стоической философии, какими-то социальными обстоятельствами. Марк Аврелий, по его словам, был настоящим «прославлением человеческой природы» (Ренан, Обручев, 1991: 17). Все это, конечно, не отрицает роли воспитания.

Но если указанные замечательные этические качества были стойкими, повседневно воспроизводились в общении и деятельности, то это свидетельствует о наличии в головном мозгу таких личностей определенных диспозициональных структур, которые определяют соответствующие им ценностные установки, коммуникативные и деятельные особенности. Пока еще нейронаука не может их четко выделить и описать, но уже получила в этом отношении ряд существенных результатов. Антонио Дамасио со своими сотрудниками провел исследование мозговых 
процессов у тех людей, которые остро переживали чувство восхищения высокими нравственными поступками другого человека и вместе с тем испытывали ярко выраженное сострадание горю другого (его «душевной боли»). При этом в их головном мозгу всегда активировались определенные области заднемедиальной коры. Интересно, что когда исследовали чувство восхищения не от высоких нравственных поступков, а от выдающихся спортивных результатов или при наблюдении результатов каких-либо других необыкновенных физических усилий, то активировалась другая область заднемедиальной коры (Дамасио, Ющенко, 2018). Это указывает на то, что существуют специфические мозговые структуры и функции, ответственные именно за нравственные качества человека. Ряд существенных данных на этот счет содержится в исследованиях неврологов и психиатров (особенно важные результаты представлены в замечательной книге В. С. Рамачандрана (Рамачандран, Чепель, 2014). Есть основания надеяться, что уже в недалеком будущем такого рода вопросы станут предметом более глубоких и основательных исследований. Нейроэтика имеет в этом плане хорошие перспективы.

\section{3. СВОБОДА ВОЛИ И СОВРЕМЕННАЯ НЕЙРОНАУКА}

Вопрос о свободе воли является ключевым для этики. Если у человека нет свободы воли, если я лишен способности по своему мысленному плану, по своему желанию и решению совершить определенное действие, независимо от наличных внешних условий, то тем самым сразу перечеркивается моральная ответственность личности за свои поступки. Bсе ее действия оказываются предопределенными уже до ее рождения в силу неразрывной физической цепи причин и следствий. Отрицание свободы воли - позиция радикального физикализма. Как утверждает ее защитник, философ Пратт, свобода воли есть иллюзия, подобная конвергенции рельсов. Каждый видит, что они вдали сходятся, но в действительности этого нет.

В последние десятилетия широко распространилось отрицание свободы воли путем ссылок на результаты нейронаучных исследований. Здесь до сих пор в центр внимания ставят нашумевшие эксперименты Б. Либета. Суть их в том, что одно из двух простейших действий, заданных испытуемому согласно инструкции, начинается и производится до того, как он осознает свое решение. Подобные эксперименты проводились и другими нейрофизиологами (Ч. Сун и др.). Они якобы доказывали отсутствие свободы воли. Однако многими учеными и философами, в том числе и в моих работах, была показана некорректность этих 
экспериментов, несостоятельность производимых на их основе выводов (Дубровский, 2017; Dubrovsky, 2019b; Мишура, 2013).

Важно подчеркнуть, что из доказательства отсутствия свободы воли в отдельных случаях, не следует, что ее вообе нет. Наоборот, доказательство, что в отдельных случаях она существует, достаточно для ее признания. Иначе говоря, для признания свободы воли, как неотъемлемого свойства человека, достаточно утверждения ее наличия в частном виде. Действительно, не все наши поступки являются актами свободной воли в том смысле, что иногда они совершаются по принуждению, вопреки нашему желанию, по жизненно важным для нас причинам (в экстремальных ситуациях и т. п.). Но мы все равно несем за них ответственность, так как сознаем это противоречие.

Некоторые отрицают свободу воли, неверно истолковывая соотношение сознательного и бессознательного в нашей жизнедеятельности или приписывая совершаемые действия не личности, нашему Я, а головному мозгу. Такой разрыв свидетельствует о непонимании органической связи нашего Я и нашего мозга. Современная нейронаука выделяет в головном мозгу его подсистему, ответственную за личностные свойства человека, сознание и волю, т. е. представляющая нам наше Я. Ее называют Самостью или Эго-системой головного мозга (Дамасио, Ющенко, 2018; Матюшкин, 2007). Она, возникает в ходе эволюции на основе протосамости (сугубо биологических форм поддержания целостности организма и использования простейших ощущений), включает базовую cамость (когда телесные ощущения и психические отображения объектов внешней среды образуют в головном мозгу единую целостную структуру) и биографическую самость с ее более высокой функциональной организацией, персональной идентичностью, ценностно-смысловыми структурами сознания, языка, памяти, а, следовательно, и нравственными регулятивами.

Это и есть Эго-система головного мозга, наше Я в нераздельном единстве ментального и телесного, со всеми столь знакомыми каждому функциями отображения, управления, мышления, мотивации и действия. Это самоорганизующаяся система, которую мы ощущаем как свое Я, способное к самотображению и самодетерминации, т. е. к произвольным действиям (по своей воле).

Здесь уместно привести слова выдающегося представителя современной нейронауки Антонио Дамасио, который внес наибольший вклад 
в исследование структуры и функций Самости, соотношения сознательных и бессознательных информационных процессов в деятельности мозга (Дамасио, Ющенко, 2018: 313):

Когда психика получает сведения о том, чем занят наш организм, увязанное с этой информацией ощущение означает, что действие происходит по воле нашей самости. Для возникновения мотивации к обдумыванию будущих действий нужны как информация, так и удостоверение подлинности текущих действий. Без ощущаемой и подтвержденной информации такого рода мы не смогли бы принять на себя моральную ответственность за действия, которые совершает наше тело.

Я остановился на этом специально, ибо модные ныне отрицания свободы воли, апеллирующие к нейронауке, основаны на непонимании характера связи явлений субъективной реальности и мозговых процессов, которая представляет собой связь информации и ее нейродинамического носителя. Это связь не причинная, а функциональная, она представляет собой сложившуюся в филогенезе или онтогенезе кодовую зависимость. Особенность этой связи состоит в том, что феномен субъективной реальности и его мозговой нейродинамический эквивалент имеют одну и ту же причину, являются одновременными и находятся в отношении взаимнооднозначного соответствия. Но это означает, что моя очевидная способность управлять по своей воле своими определенными образами или мыслями (в довольно широком диапазоне) означает мою способность произвольно управлять соответствующим классом моих собственных мозговых нейродинамических систем. Мы постоянно, не зная, не чувствуя, делаем это. Иногда не лучшим образом. Но именно эта способность, выражающая суть самоорганизации, самодетерминации, саморегуляции нашей мозговой Эго-системы, следовательно нашего Я, лежит в основе свободы воли. Разумеется, диапазон возможных произвольных действий ограничен, мы постоянно стремимся его расширить и во многих случаях нам это удается.

А теперь я хочу привести несколько примеров того, к каким последствиям приводит непонимание действительной связи нашего Я, как субъективной реальности, с нашим мозгом. Недавно вышел русский перевод книги известного немецкого философа Томаса Мецингера «Наука о мозге и миф о своем Я. Тоннель Эго». В аннотации к ней, подготовленной автором, читаем: «Она объясняет, почему все наши интуитивные представления о собственном разуме неверны и почему человеческой личности просто не существует» (Мецингер, Соловьева, 2017). 
Разумеется, в таком случае не существует и свободы воли. Особенно интересно, что все это автор прилагает ко всем нам, но не прилагает к самому себе! Сам он, поскольку пишет книги и учит нас, считает себя, конечно, личностью, но, выходит, единственной во всем человечестве. Знакомый феномен, который я называю «отрешенностью от себя»: когда теоретик, с уверенностью высказывающий общие заключения о человеке, сознании, мышлении и т. п., не относит этого к самому себе. Тем самым он сразу лишает достоинства свои теоретические построения, а заодно нарушает в своей «гордыне» и элементарные этические принципы науки. Здесь нет возможности критически разбирать книгу Томаса Мецингера. Поэтому достаточно сказанного.

Хочу еще раз отметить, что отрицание свободы воли (в той или иной интерпретации) стало в последнее время очень модным. Оно не раз звучало в устных публичных выступлениях одного из наших ведущих специалистов в области когнитивных наук Татьяны Владимировны Черниговской. Близкую позицию занимает, как ни странно, и такой крупный мыслитель нашего времени как Юваль Ной Харари, который в своем знаменитом трехтомнике не раз возвращается к этому вопросу.

Его отношение к понятию «свободы воли» воли связано с критикой идеологии либерализма, и эта критика заслуживает во многом внимания и поддержки. Тем не менее, развиваемые им взгляды по этому вопросу, на мой взгляд, довольно противоречивы. Он признает, что свобода является «базовой ценностью», но далее не раз ставит это под вопрос (Харари, Гольдберг, 2019: 357):

Либеральная история призывает меня искать свободу самовыражения и самореализации. Но «личность» и «свобода»- мифологические химеры, позаимствованные из волшебных сказок древности. Больше всего путаницы либерализм вносит в понятие «свободы воли». Совершенно очевидно, что у человека есть воля и желания - а порой и возможность исполнять эти желания. Если под «свободой воли» вы понимаете свободу делать то, что хотите, то да, люди обладают свободой воли. Но если под «свободой воли» подразумевается свобода выбирать желания, то такой свободы у человека нет.

И автор иллюстрирует это следующим образом (там же: 357-358):

Если меня привлекают мужчины, я волен реализовывать свои фантазии, но не свободен чувствовать влечение не к мужчинам, а к женщинам. Я мог бы решить, что буду сдерживать свои сексуальные желания, или даже пройти терапию «смены пола», но даже само желание изменить сексуальную ориентацию будет результатом взаимодействия нейронов- возможно под влиянием культурных и религиозных предрассудков. 
Обратите, однако, внимание: даже на столь «ярком» примере мы видим, что человек по своей воле все-таки может изменять свои желания, «выбирать желания» и осуществлять их, если не сегодня, то завтра. Что касается «результата взаимодействия нейронов», то об этом дальше будет особый разговор. Сначала посмотрим на «культурные и религиозные предрассудки». В их число у автора, конечно, включены нравственные ценности и установки. Ведь именно под их воздействием достигается изменение «нежелательных» желаний, стойких вредных привычек и склонностей. Всем нам известно множество примеров, когда под влиянием долга и других нравственных установок человек преодолевает свои привычные сильные желания и склонности, унижающие в собственных глазах его достоинство. Но ведь известны и такие факты, когда человек совершает нравственный подвиг самопожертвования: его главное человеческое желание - сохранить свою жизнь - уступает место непреклонному желанию выполнить свой нравственный, гражданский долг. Такова сила высоких нравственных убеждений.

Да, не каждый это может. Но некоторые могут! А это позволяет не ограничивать диапазон свободы воли так, как это делает Харари. Именно высокие нравственные принципы способны служить укреплению и развитию силы духа, силы воли, решению самых трудных задач, которые сознательно ставит перед собой человек.

Теперь об изменениях желаний как «результате взаимодействия нейронов». Здесь у автора проявляется разрыв между явлениями субъективной реальности в форме желаний (мыслей, решений и т. п.) и мозговыми процессами, о чем речь уже шла выше. Это следствие недостаточной компетенции в области современной нейронауки, изучающей сознание. Все явления сознания необходимо связаны с «взаимодействием нейронов». Но каждое явление сознания имеет свой нейродинамический эквивалент; поэтому разрывать их, противопоставлять друг другу в качестве разных причин, по меньшей мере, теоретически не корректно.

Когда пытаются рассуждать о реальном действии нравственной установки личности, которая выражается в соответствующем поступке, то надо иметь в виду, что содержание этой установки представлено в мозгу в виде определенной нейродинамической структуры, которая, будучи активирована, служит причиной цепи соматических и поведенческих изменений, образующих данный поступок. Нравственная установка, как психическое явление, может вполне обоснованно, строго научно рассматриваться в качестве причины нравственного поступка. Психическая 
причина есть вид информационной причины. Она отличается от физической причины тем, что вызываемое ей следствие определяется именно информацией, как таковой, а не физическими свойствами ее носителя, поскольку они могут быть разными (в силу принципа инвариантности информации по отношению к физическим свойствам ее носителя; одна и та же информация может кодироваться по-разному).

Разумеется, как и всякая нейродинамическая структура, «взаимодействие нейронов» органически включает синаптические, электрические, биохимические процессы. Однако важно четко различать в ее организации (как целостного информационного паттерна) эти «нижележащие» уровни. Из самого полного описания биохимических процессов (т.е. молекулярного уровня) нельзя получить объяснения нравственного поступка и даже его отдельных компонентов. Биохимические процессы, безусловно, лежат в основе жизнеобеспечения нейронов и их взаимодействия. Но важно учитывать и то принципиальное обстоятельство, что нейродинамические структуры высшего уровня мозговой самоорганизации, ответственные за сознательные действия, обладают способностью нисходящего причинного влияния на молекулярные структуры генетического уровня. Показано, например, что даже простые когнитивные мыслительные операции сразу вызывают экспрессию так называемых быстрых генов.

Я затронул вопрос о биохимических, электрических, синаптических процессах в связи с тем, что у Харари встречаются попытки напрямую использовать их для объяснения осознаваемых явлений социального, в том числе этического порядка (Харари, Сумм, 2016: 471):

Как любое состояние души, субъективное ощущение счастья определяется не внешними параметрами - жалованьем, системой отношений, политическими правами, - а сложной системой нервов, нейронов, синапсов и биологически активными веществами: серотонином, дофамином и окситоцином.

[...] Долговечное счастье приходит лишь изнутри-это серотонин, дофамин и окситоцин.

[...] Поправим свою биохимию. Если вложить миллиарды в разгадку биохимического кода и в поиск соответствующих лекарств, мы сделаем людей намного счастливее без всяких революций. Прозак, к примеру, никак не покушаясь на государственный строй, повышает уровень серотонина в крови и выводит пациента из депрессии (там же: 470).

Такие слишком прямолинейные суждения, на мой взгляд, вызывают возражение, так как они смешивают, не различают высшие и низшие 
уровни мозговых процессов, определяющих сознательную деятельность. Понятно стремление автора подчеркнуть роль генетических факторов, различие индивидов по своим врожденным задаткам, а соответственно, и особенности у каждого биохимических показателей. О генетической зависимости ряда весьма существенных свойств индивидуального и массового сознания говорилось выше, но даже и они могут, в принципе, быть предметом преобразований. Указанная прямолинейность упрощает реальную сложность, сплющивает многомерность организации сознательных процессов, не оставляет места для свободы воли, творческой деятельности личности.

Вместе с этим автор высказывает ряд глубоких мыслей об ограниченности человеческого разума, его перспективах в связи с развитием искусственного интеллекта, справедливо подчеркивает исключительную важность разработки проблемы сознания на нынешнем этапе развития нашей цивилизации. Крайне актуальным является осмысление тех негативных свойств массового сознания, которые связаны с природой человека, воспроизводятся во все эпохи, у всех народов, что указывает на их биологическую, генетическую обусловленность, трудности их изменения. Развитие искусственного интеллекта идет нарастающими темпами. Мы рискуем оказаться «под властью алгоритмов». Автор остро ставит вопросы, касающиеся будущего земной цивилизации. Его трехтомник охватывает практически все основные контексты проблемы человека. При этом в некоторых из них его позиция о свободе воле сильно меняется. Он фактически прямо признает свободу воли личности и ее ответственность, причем не только за собственные поступки, но и за результаты действий других. Он подчеркивает, что

... светские люди ценят ответственность. Они не верят в высшую силу, которая заботится о мире, наказывает злых, воздает справедливым и защищает от голода, эпидемий или войн. Поэтому именно мы, смертные люди из плоти и крови, должны нести полную ответственность за свои действия или бездействие. Если мир полон страданий, наш долг-найти решение (Харари, Гольдберг, 2019: 256).

И он продолжает (там же: 257):

мы должны нести полную ответственность за все преступления и ошибки современного общества, от геноцида до ухудшения экологии. 
В заключение хотелось бы настоятельно подчеркнуть, что вопросы нейроэтики должны рассматриваться не только в своих многочисленных частных ракурсах, но и в двух широких взаимосвязанных контекстах, имеющих судьбоносное значение для будущего нашей цивилизации, контекстах, которые были многопланово и основательно рассмотрены в трехтомнике Харари. Речь идет о неуклонно нарастающем глобальном кризисе земной цивилизации, ведущем ее к гибели, и об антропотехнологической эволюции, которая представляет собой коэволюцию сознания, телесности, среды и технологий, ведет к преобразованию человека и общества и дает надежду на преодоление глобального кризиса, выход земной цивилизации на качественно новый этап развития.

По мере нарастания глобального кризиса особенно остро встает проблема сознания, изменения его негативных свойств, таких как неуемное потребительство, агрессивность, крайнее эгоистическое своеволие. Иногда это частично достигается воспитанием, влиянием религии, идеологии, социальных факторов, но все они, как свидетельствует исторический опыт, слишком далеки от способности решения проблемы, не в состоянии предотвратить угрозу гибели человечества. На нынешнем этапе антропотехнологической эволюции для преодоления негативных свойств сознания не исключается использование специальных средств нейронауки и технологий. Практические возможности этого, принципиальные этические, юридические и экзистенциальные вопросы довольно широко обсуждаются в современной литературе. Но эта острая дискуссионная тема оставляет пока множество неопределенностей, требует настойчивого пристального анализа. Это относится и к осмыслению процессов антропотехнологической эволюции, темпы которой тоже нарастают, открывая новые творческие возможности нашего разума и тем самым новые формы его самопреобразования, включая и его экзистенциальные, нравственные регистры. Философы и наша так называемая интеллектуальная элита, как ни странно, не уделяют должного внимания этим первостепенным жизненно значимым проблемам. В последние месяцы, выступая с докладами в разных, иногда довольно многочисленных, философских аудиториях, я просил присутствующих ответить на вопрос: кто читал «Второе предупреждение ученых мира человечеству», которое подписали более 15000 ученых из 184 стран? В нем документально показаны те катастрофические изменения, которые произошли на нашей планете за последние 25 лет (со времени «Первого предупреждения»); они касаются не только экологической системы, но 
и глобальных планетарных физико-химических процессов, многие из которых достигли необратимого рубежа и влекут гибельные последствия. K моему удивлению, в нескольких сравнительно больших аудиториях, примерно из 100 присутствующих об этом слышали два-три человека (но не читали), в других вообще никто об этом ничего не знал, и только в двух аудиториях нашлось три человека, прочитавших этот документ.

Создается впечатление, что наша философская общественность в большинстве своем успешно вытесняет из своего сознания эти судьбоносные проблемы, остается «спокойна» в духовно-нравственном отношении, лишенная ощущения холодных дуновений надвигающегося небытия, она продолжает свое профессиональное существование в рамках парадигм классической философии прошлых веков, рассчитанных как бы на вечное, необозримо долгое, бытие человечества. Но наше время настоятельно требует новых подходов к задачам философии, в том числе к осмыслению ее экзистенциальных и нравственных основ.

\section{Литература}

Дамасио А. Я : Мозг и возникновение сознания / пер. с англ. И. Ющенко. М. : Карьера-Пресс, 2018.

Дубровский Д. И. Обман : философско-психологический анализ. - М. : Канон+, 2010.

Дубровский Д. И. Проблема «Сознание и мозг» : Теоретическое решение. М. : Канон +, 2015.

Дубровский Д. И. Проблема свободы воли и современная нейронаука // Журнал высшей нервной деятельности. — 2017. - Т. 67, № 6. - С. 739-754.

Матюшкин Д. П. О возможных нейрофизиологических основах природы внутреннего «Я» человека // Физиология человека. - 2007. - Т. 33, № 4. - С. 1-10. Мецингер Т. Наука о мозге и миф о своём Я : Тоннель Эго / пер. с англ. Г. Соловьевой. - М. : АСТ, 2017.

Мишура A. С. Проблема свободы воли и нейропсихология // Психология. Историко-критические обзоры и современные исследования. - 2013. - Т. 1, № 2. - C. 6-29.

Рамачандран B. C. Мозг рассказывает : что делает нас людьми / пер. с англ. Е. Чепель. - М. : Карьера-Пресс, 2014.

Ренан Э. Марк Аврелий и конец античной эпохи / пер. с фр. В.А. Обручева. - М. : Терра, 1991.

Светоний Гай Транквилл. Жизнь двенадцати цезарей / пер. с лат. М. Л. Гаспарова. - М. : Наука, 1966.

Харари Ю. Н. Sapiens : Краткая история человечества / пер. с англ. Л. Сумм. М. : Синдбад, 2016. 
Харари Ю.Н. 21 урок для ХХІ века / пер. с англ. Ю. Гольдберга. - М. : Синдбад, 2019.

Эфроимсон В. П. Генетика этики и эстетики. - М. : Тайдекс Ko, 2004.

Dubrovsky D. I. Does Brain Research Make Reading Another's Thoughts Possible? //

Russian Studies in Philosophy. - 2018. - Vol. 56, no. 1. - P. 18-28.

Dubrovsky D. I. "The Hard Problem of Consciousness" : Theoretical Solution of its Main Questions // AIMS Neuroscience. - 2019a. - Vol. 6, no. 2. - P. 85-103.

Dubrovsky D. I. The Problem of Free Will and Modern Neuroscience // Neuroscience and Behavioral Physiology. - 2019b. - Vol. 49, no. 5. - P. 629-239.

Levy N. Neuroethics : Challenges for the 21st Century. - Cambridge : Cambridge University Press, 2007 .

Miyawaki Y., Uchida H., Yamashita O. Visual Image Reconstruction from Human Brain Activity Using a Combination of Multi-Scale Local Image Decoders // Neuron. - 2008. - Vol. 6o, no. 5. - P. 915-929.

Nishimoto S., Naselaris T., Benjamini Y. Reconstructing Visual Experiences from Brain Activity Evoked by Natural Movies // Current Biology. - 2001. - Vol. 21, no. 19. - P. 1641-1646.

Dubrovskiy, D. I. 2020. "Neyroetika: nekotoryye aktual'nyye filosofsko-metodologicheskiye voprosy [Neuroethics: Some Relevant Philosophical and Methodological Issues]" [in Russian]. Filosofiya. Zhurnal Vysshey shkoly ekonomiki [Philosophy. Journal of the Higher School of Economics] IV (1), 24-41.

\title{
DAVID DUBROVSKIY
}

Doctor of Letters in Philosophy; Leading Researcher at the Institute of Philosophy, Russian Academy of Sciences, Moscow

\section{Neuroethics: Some Relevant Philosophical AND Methodological Issues}

\begin{abstract}
I distinguish two main aspects of neuroethics in the article: neuroscientific studies of ethically significant properties of consciousness and the tasks of ethical regulation and ethical control of modern neuroscience studies of consciousness and the brain. Next, three topical issues are discussed regarding the designated aspects of neuroethics: (1) Ethical problems in the area of neuroscience research, called Brain-Reading, which deals with the determination of brain correlates of psychic phenomena and the deciphering of their neurodynamic codes. There are acute ethical and social issues questions about the legitimacy of the invasion of the subjective world of the personality, which require a thorough discussion. (2) Neuroscientific and genetic studies of the phenomenon of deception as a factor of interpersonal and social communications, emphasizes the importance of taking into account various forms of deception and the corresponding dispositional properties of consciousness, the experience of neuroscientific research of these properties and those dispositional properties that determine the installation of the truth and the realization of high moral qualities of a person is shown. The ethical legitimacy of exposing malicious fraud using neuroscientific methods, especially in
\end{abstract}


cases of criminal acts, is shown. (3) Critically analyzed are attempts to deny free will through references to neuroscience research. The issue of free will is the key to ethics. The bankruptcy of several currently fashionable concepts that deny free will and thereby contribute to the spread of moral relativism is shown.

Keywords: Neuroethics, Neuroscience, Genetics, Consciousness, Brain-Reading, Deception $\&$ Its Neuroscientific Research, Free Will \& Neuroscience, Criticism of the Denial of Free Will.

DOI: $10.17323 / 2587-8719-2020-1-24-41$.

\section{REFERENCES}

Damasio, A. [Damasio, A.] 2018. Ya [Self Comes to Mind]: Mozg i vozniknoveniye soznaniya [Constructing the Conscious Brain] [in Russian]. Trans. from the English by I. Yushchenko. Moskva [Moscow]: Kar'yera-Press.

Dubrovskiy, D. I. 2010. Obman [Deception]: filosofsko-psikhologicheskiy analiz [A Philosophical and Psychological Analysis] [in Russian]. Moskva [Moscow]: Kanon+.

- 2015. Problema "Soznaniye $i$ mozg" [The Problem of "Consciousness and the Brain"]: Teoreticheskoye resheniye [Theoretical Solution] [in Russian]. Moskva [Moscow]: Kanon+.

. 2017. "Problema svobody voli i sovremennaya neyronauka [The Problem of Free Will and Modern Neuroscience]" [in Russian]. Zhurnal vysshey nervnoy deyatel'nosti [Journal of Higher Nervous Activity] 67 (6): 739-754.

Dubrovsky, D.I. 2018. "Does Brain Research Make Reading Another's Thoughts Possible?" Russian Studies in Philosophy 56 (1): 18-28.

. 2019a. "'The Hard Problem of Consciousness': Theoretical Solution of its Main Questions." AIMS Neuroscience 6 (2): 85-103.

2019b. "The Problem of Free Will and Modern Neuroscience." Neuroscience and Behavioral Physiology 49 (5): 629-239.

Efroimson, V.P. 2004. Genetika etiki i estetiki [Genetics of Ethics and Aesthetics] [in Russian]. Moskva [Moscow]: Taydeks Ko.

Kharari, Yu. N. [Harari, Y. N.] 2016. Sapiens [Sapiens]: Kratkaya istoriya chelovechestva [A Brief History of Humankind] [in Russian]. Trans. from the English by L. Summ. Moskva [Moscow]: Sindbad.

. 2019. 21 urok dlya XXI veka [21 Lessons for the 21st Century] [in Russian]. Trans. from the English by Yu. Gol'dberg. Moskva [Moscow]: Sindbad.

Levy, N. 2007. Neuroethics: Challenges for the 21st Century. Cambridge: Cambridge University Press.

Metsinger, T. [Metzinger, T.] 2017. Nauka o mozge i mif o svoyëm Ya [The Science Of The Mind And The Myth Of The Self ]: Tonnel' Ego [The Ego Tunnel] [in Russian]. Trans. from the English by G. Solov'yeva. Moskva [Moscow]: AST.

Mishura, A.S. 2013. "Problema svobody voli i neyropsikhologiya [The Problem of Free Will and Neuropsychology]" [in Russian]. Psikhologiya. Istoriko-kriticheskiye obzory i sovremennyye issledovaniya [Psychology. Historical-Critical Reviews and Current Researches] 1 (2): 6-29.

Miyawaki, Y., H. Uchida, and O. Yamashita. 2008. "Visual Image Reconstruction from $\mathrm{Hu}-$ man Brain Activity Using a Combination of Multi-Scale Local Image Decoders." Neuron 60 (5): 915-929.

Nishimoto, S., T. Naselaris, and Y. Benjamini. 2001. "Reconstructing Visual Experiences from Brain Activity Evoked by Natural Movies." Current Biology 21 (19): 1641-1646. 
Ramachandran, V.S. [Ramachandran, V.] 2014. Mozg rasskazyvayet [The Tall-Tale Brain]: chto delayet nas lyud'mi [A Neuroscientist's Quest for What Makes Us Human] [in Russian]. Trans. from the English by Ye. Chepel'. Moskva [Moscow]: Kar'yera-Press.

Renan, E. [Renan, E.] 1991. Mark Avreliy i konets antichnoy epokhi [Marc-Aurèle et la fin $d u$ monde antique] [in Russian]. Trans. from the French by V. A. Obruchev. Moskva [Moscow]: Terra.

Svetoniy Gay Trankvill [Suetonius Gaius Tranquillus]. 1966. Zhizn' dvenadtsati tsezarey [De vita Caesarum] [in Russian]. Trans. from the Latin by M. L. Gasparov. Moskva [Moscow]: Nauka. 